\title{
ESTIMATES OF SEASONAL SIGNALS IN GNSS TIME SERIES AND ENVIRONMENTAL LOADING MODELS WITH ITERATIVE LEAST-SQUARES ESTIMATION (iLSE) APPROACH
}

\author{
Adrian KACZMAREK* and Bernard KONTNY
}

Institute of Geodesy and Geoinformatics, Wroclaw University of Environmental and Life Sciences, Grunwaldzka 53, 50-357 Wroclaw, Poland

*Corresponding author's e-mail: adrian.kaczmarek@upwr.edu.pl

\begin{tabular}{l} 
ARTICLE INFO \\
\hline Article history: \\
Received 20 February 2018 \\
Accepted 31 May 2018 \\
Available online 30 May 2018
\end{tabular}

Keywords:

Coordinates time series

Loading models

Cross-correlation

Phase shift

Correlation coefficient

Wavelet analysis

Seasonal signal

\begin{abstract}
The GNSS (Global Navigation Satellite System) coordinates time series are still used as a source for determining the velocities of GNSS permanent stations. These coordinates, apart from the geodynamical signals, also contain an interference signal. This paper shows the results of the comparative analysis of the GNSS coordinates time series with a deformation of the Earth's crust obtained from loading models. In the analysis, coordinates time series are used (CODE Repro2013) without loading models (Atmospheric Pressure Loading, Hydrology, Non-Tidal Ocean Loading) at the stage of the reprocessing of GNSS archival data. The analyses showed that in the case of the Up component there is a high correlation between the GNSS coordinates changes and deformations of the Earth's crust from the loading models (coefficient 0.5-0.8). Additionally, we noticed that for horizontal components (North, East) changes occur in the phase shift between coordinates, and the Earth's crust deformations signals are accelerated or delayed each other (-150 to 200 days). This article shows new methods of iLSE (iteration Least Square Estimation) to determine periodic signals in the time series. Additionally, we compared the values of estimated amplitudes for GNSS and deformation time series.
\end{abstract}

\section{INTRODUCTION}

The coordinate time series is the basis for determining both position and velocity changes of the permanent stations of the Global Navigation Satellite System (GNSS). In the coordinate time series, we can extract the linear or non-linear trend, the annual and semiannual signals, discontinuities and the measurement noise. The majority of analyses focus on determining the annual signals, then investigating discontinuities in the time series, and finally on estimating reliable station velocity changes, e.g., for the determination of tectonic movements (Bos et al., 2010). Some papers are also devoted to the investigation of how measurement noise influences the coordinate time series (Bogusz and Kontny, 2011; Williams et al., 2004). The reliability of all the stations' velocity components mainly depends on both proper modelling of the deterministic part of the signal and the assumption (selection) of the optimal character of the stochastic part of coordinate time series residuals (Kłos et al., 2018). In the deterministic part, discontinuities may occur that are caused by measurement equipment exchanges, human-induced local deformations or tectonic movements together with earthquakes. These changes can lead to the misinterpretation of the coordinate time series (Kłoset al., 2014, 2015).
The literature devoted to the analysis of GNSS coordinate time series reports examples of the wrong assumption of the annual changes which lead to overestimation of station velocities (Bos et al., 2010). Dong et al. (2002) showed that the atmospheric pressure loading (APL), snow loading, and soil moisture are the main causes of annual oscillations for the Up component of GNSS permanent stations. Bogusz et al. (2012) indicated a lack of modelling of appropriate factors during GNSS raw data calculation, i.e., seasonal events caused by the atmosphere and hydrology, episodic (natural or anthropogenic seismic) and also local events caused by the frozen soil or the snow cover loading. Tregoning et al. (2009) performed the detection of the hydrological deformations using Global Positioning System (GPS) and Gravity Recovery and Climate Experiment (GRACE) data for globally distributed stations. The comparison between the GPS coordinate time series and the deformations caused by the changes of the snow cover detected by the GRACE mission resulted in the improvement of RMS with respect to the results provided by van Dam et al. (2007) and King et al. (2006), despite the lack of correlation between the above-mentioned data. The lack of correlation was caused by error in the analysis of the GPS signal, thus the authors suggest that during analysis of the GPS 
signal one has to follow the latest calculation strategies in order to reduce both the annual and semiannual signals. Additionally, the authors showed that the local hydrological processes have a significant impact on changes in the coordinate time series, but they are too small to be identified by the GRACE mission. The authors also found, contrary to the horizontal component of station coordinates, a high correlation between GPS-derived coordinates anomalies and the GRACE-derived height coordinates.

Jiang et al. (2013) showed the methods for estimating loadings caused by the geophysical fluids used to indicate the Earth's crust displacement and determined the non-linear correlation of those changes with the Up component of the coordinate time series. The data needed for the calculation of loadings caused by geophysical fluids are provided by the Global Geophysical Fluid Center (GGFC), the Loading Model of Quasi-Observation Combination Analysis software (QLM) and the author's time series loading model, i.e., the Optimum Data Model (ODM) provided with 1-day sampling. The authors believe that the ODM is characterized by the least scattering in the Up component of the GPS time series, GGFC is characterized by the highest stability, and QLM is characterized by the biggest scattering. Removing the loading impact from the GPS coordinate time series enables us to reduce the scattering of the height component to the level of $74 \%, 64 \%$ and $41 \%$ using ODM, GGFC, and QLM, respectively. The QLM and GGFC models are suitable for non-specialists who need a ready service for calculating the environmental loading effects. The GGFC model is more efficient than QLM in terms of the calculation of the environmental loading application for the GPS coordinate time series, especially for the Up component. Additionally, the authors point out that the data from the GGFC model for Greenland are not accurate. This is because the hydrology data provided by GLDAS (Global Land Data Assimilation System) are not accurate enough for Greenland.

The goal of this paper is to find the correlation between the GNSS coordinate time series from the observation data and environmental phenomena such as hydrology, atmospheric pressure loading, and nontidal ocean loading (NTOL). These interference factors are not included during the calculation of GNSS data by the analysis centres of the International GNSS Service (IGS, Dow et al., 2009), e.g., by the Center for Orbit Determination in Europe (CODE, Prange et al., 2017), one of the analysis centres which performed the reprocessing of the archival GNSS data, i.e., CODE Repro2013 ${ }^{1}$. The consideration of the above mentioned factors may improve the quality of the station coordinates estimates, especially for the Up component. Additionally, in the literature, this subject is discussed mainly for the Up component whereas, in this paper, the authors analyze also the impact of the geophysical fluids on the changes of the horizontal components of station coordinates.

The analyses and conclusions below were prepared on the basis of all the analyzed GNSS permanent stations (selected stations. See chapter: Input data). This article shows only exemplary analyses.

\section{INPUT DATA}

The data used in our analysis were obtained from the online services which provide the data free of charge and available for every user. The GNSS coordinate time series were provided in the Solution INdependent EXchange format (SINEX) by CODE and represent the second reprocessing of the IGS data since 1994 (CODE Repro2013). The full description of the reprocessing strategy is available at CODE's FTP ${ }^{2}$. The reprocessing was performed in the Bernese GNSS Software 5.2 (Dach et al., 2015). For the period 1994-2001 only GPS observations were used, whereas for the period 2002-2013 the GPS+GLONASS observations were used. During the second reprocessing, IGS did not recommend applying a priori modelled loading estimates to raw GNSS data ${ }^{3}$. The coordinate time series is in the uniform reference frame IGb08 (Fig. 1).

Data on the Earth's crust deformations caused by the changes of hydrology (1-month sampling), atmospheric pressure loading (6-hour sampling) and non-tidal ocean loading (12- hour sampling) are also available at the online service "Analysis tool for geophysical fluid models ${ }^{4}$ (Fig. 2).

The abovementioned data are the result of the DFG (German Research Foundation) project (DFG Research Unit: "Space-Time Reference Systems for Monitoring Global Change and for Precise Navigation in Space"5. The resulting model is the compilation of different loading models from different analysis centres to one resolution (Table 1).

The service provides the data concerning the deformation of the Earth's crust for the North, East, and Up components in spatial resolution $2.5^{\circ} \times 2.5^{\circ}$. Additionally, this service automatically calculates the deformations time series for the chosen station. This relieves the user from using the Green's function.

\section{METHODOLOGY}

For the analysis, we chose a set of globally distributed permanent GNSS stations located both close to the coastlines and deep inland (Fig. 3).

In the analysis, we calculated periodic signals in order to indicate seasonal events. We calculated the period using the iteration Least Square Estimation method (iLSE, Eq. (1)) and the Fast Fourier

ftp://ftp.aiub.unibe.ch/REPRO 2013/CODE/- accessed 10.02.2018

ftp://ftp.aiub.unibe.ch/REPRO_2013/CODE_REPRO_2013.ACN- accessed 10.02.2018

http://acc.igs.org/reprocess $2 . \mathrm{html}$ - accessed 10.02.2018

${ }^{4}$ http://ida.bkg.bund.de/refsys/web/?Projects__Project_5___Results - accessed 10.02.2018

${ }^{5} \mathrm{http}$ ://ida.bkg.bund.de/refsys/web/?Projects_Project_5 - accessed 10.02.2018 

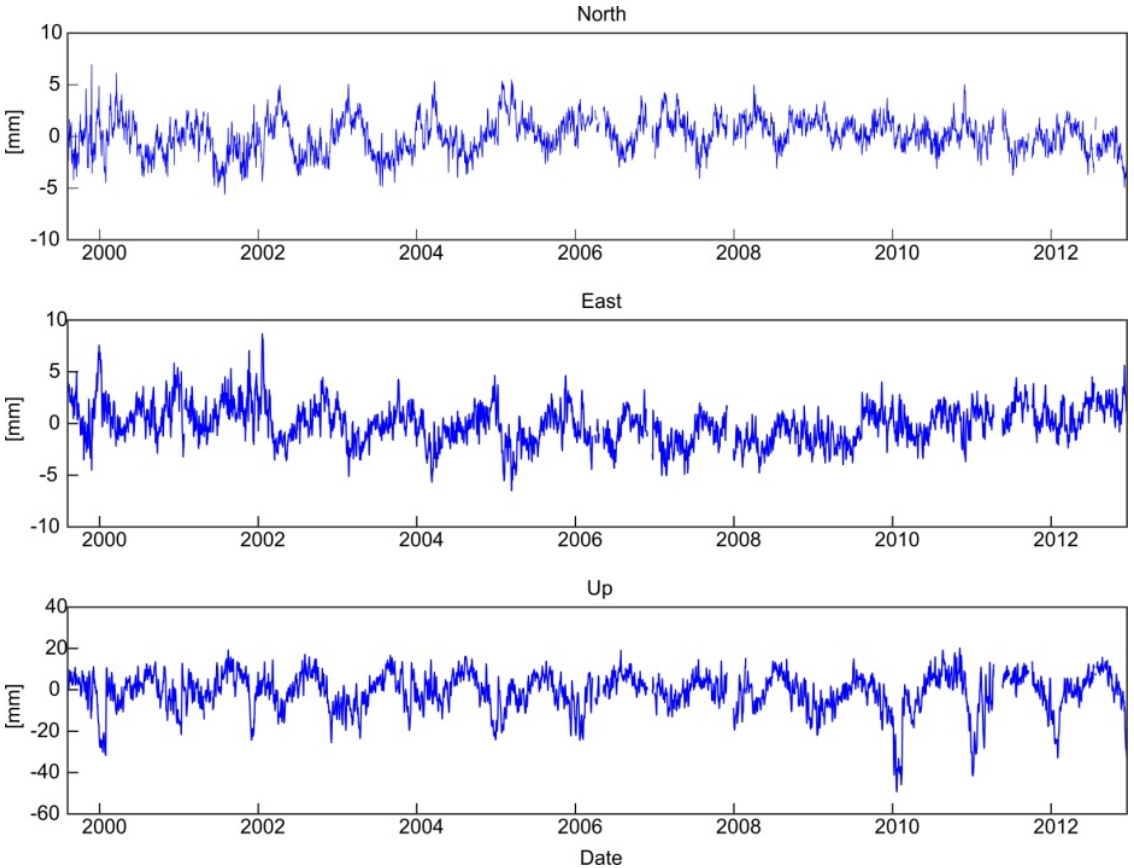

Fig. 1 Example of coordinate time series for ARTU (Arti, Russian Federation) station (after removing linear trend).
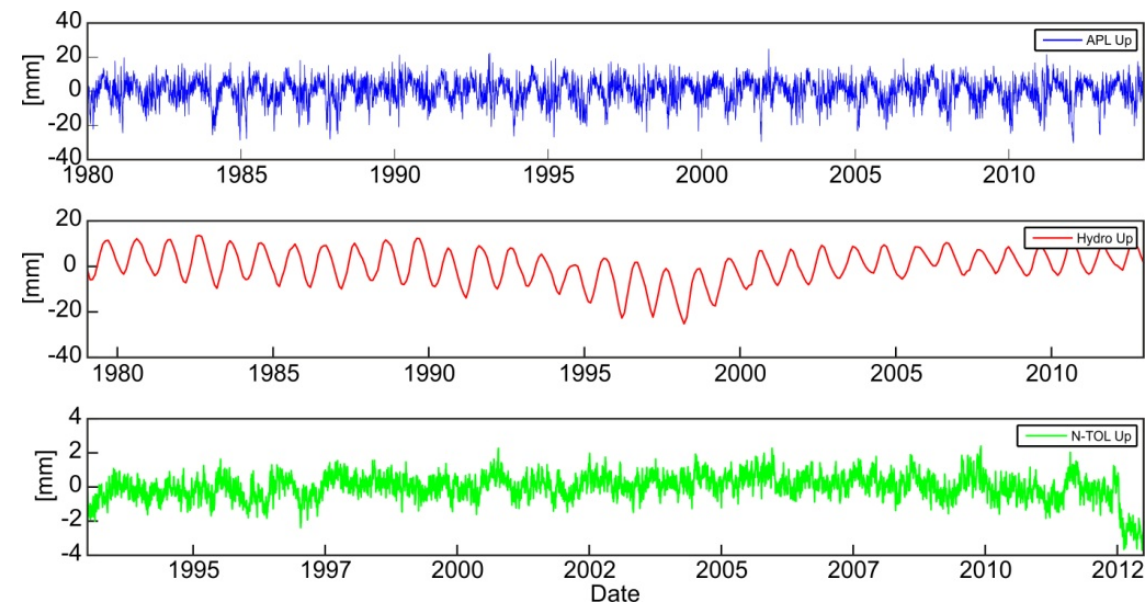

Fig. 2 Example of deformation of the Earth's crust time series (APL; Hydro (Hydrology); NTOL).

Transform (FFT). This method (iLSE) was applied to find periodic oscillation in the GNSS coordinate time series and deformation time series. The iLSE method is shown in the following formula:

$y_{i}(t)=A_{s_{i}} \cdot \sin \left(\frac{2 \pi}{T_{i}} \cdot t\right)+A_{c_{i}} \cdot \cos \left(\frac{2 \pi}{T_{i}} \cdot t\right)$

where: $t$ - time,

$T_{i}-$ period $(1,2,3, \ldots, \mathrm{n})$,

$A_{s_{i}}, A_{c_{i}}$ - estimation of function coefficients,

$y_{i}(t)$ - model of the time series.

After each iteration, we calculated the residuals (Eq. (3)) and the sum of residual squares (Eq. (2)). The minimum sum of residual squares determines a period in the time series occurring. The value of the periodic signal which appears in the data is defined by the following formulae:

$$
\begin{array}{r}
p(T)=\min \left[\sum \operatorname{resid}_{T_{i}}^{2} ; \ldots ; \sum \operatorname{resid}_{T_{n}}^{2}\right] \\
\operatorname{resid}(t)=\operatorname{data}(t)-y_{i}(t)
\end{array}
$$

where:

$p(T)$ - value of periodic signal appearing in the time series,

$\operatorname{resid}(t)$ - residual between model and coordinates, data $(t)$ - input time series.

Additionally, we analyzed the phase shift of the annual signal. The phase shift between signals is defined by the following formula:

$\operatorname{lag}=\max (x \operatorname{corr}(A, B))$

where:

lag - phase difference between signals (unit: days),

$A, B$ - input model signals,

xcorr - cross-correlation function. 
Table 1 Models used for the calculation of the Earth's crust deformations (Analysis tool for geophysical fluid models $)^{6}$.

\begin{tabular}{|c|c|c|c|c|}
\hline \multicolumn{5}{|c|}{ Atmosphere } \\
\hline Analysis Centre & Temp. Res. & Spatial Res. & Time Span & Model \\
\hline Uni Luxembourg & $6 \mathrm{~h}$ & $2.5^{\circ}$ & $1980-2014$ & NCEP \\
\hline NASA GSFC & $6 \mathrm{~h}$ & $2.5^{\circ}$ & $1976-2014$ & NCEP \\
\hline TU Vienna (V4) & $6 \mathrm{~h}$ & $1^{\circ}$ & $1994-2014$ & ECMWF \\
\hline Uni Strasbourg & $3 \mathrm{~h}$ & $0.5^{\circ}$ & $2001-2014$ & ECMWF + IB \\
\hline & $3 \mathrm{~h}$ & $0.5^{\circ}$ & $2002-2013$ & $\mathrm{ECMWF}+\mathrm{MOG} 2 \mathrm{D}$ \\
\hline & $6 \mathrm{~h}$ & $0.5^{\circ}$ & $1979-2014$ & ERAinterim + IB \\
\hline International Mass Loading & $6 \mathrm{~h}$ & $1^{\circ}$ & $2000-2014$ & MERRA \\
\hline (IMLS) & $3 \mathrm{~h}$ & $1^{\circ}$ & $2012-2013$ & GEOS-57 \\
\hline & $3 \mathrm{~h}$ & $1^{\circ}$ & $2013-2014$ & GEOS-FP \\
\hline & $3 \mathrm{~h}$ & $1^{\circ}$ & $2013-2014$ & GEOS-FPIT \\
\hline \multicolumn{5}{|c|}{ Ocean } \\
\hline Uni Luxembourg & $12 \mathrm{~h}$ & $2.5^{\circ}$ & $1993-2012$ & ECCO1/JPL \\
\hline NASA GSFC & $12 \mathrm{~h}$ & $1^{\circ}$ & $1993-2013$ & $\mathrm{ECCO} 1 / \mathrm{JPL}$ \\
\hline $\begin{array}{l}\text { International Mass Loading } \\
\text { Service(IMLS) }\end{array}$ & $6 \mathrm{~h}$ & $1^{\circ}$ & $2012-2014$ & OMCT \\
\hline \multicolumn{5}{|c|}{ Hydrology } \\
\hline Uni Luxembourg & 1 month & $2.5^{\circ}$ & $1979-2012$ & GLDAS/NOAH $1^{\circ}$ \\
\hline NASA GSFC & 1 month & $1^{\circ}$ & $1979-2014$ & GLDAS/NOAH $1^{\circ}$ \\
\hline \multirow[t]{2}{*}{ Uni Strasbourg } & $3 \mathrm{~h}$ & $0.5^{\circ}$ & $2001-2014$ & GLDAS/NOAH $0.25^{\circ}$ \\
\hline & $6 \mathrm{~h}$ & $0.5^{\circ}$ & $1979-2014$ & ERAinterim \\
\hline International Mass Loading & $3 \mathrm{~h}$ & $1^{\circ}$ & $2013-2014$ & MERRA \\
\hline \multirow[t]{2}{*}{$($ IMLS $)$} & $3 \mathrm{~h}$ & $1^{\circ}$ & $2012-2014$ & GEOS-FPIT \\
\hline & $3 \mathrm{~h}$ & $1^{\circ}$ & $2013-2014$ & GLDAS/NOAH $0.25^{\circ}$ \\
\hline
\end{tabular}

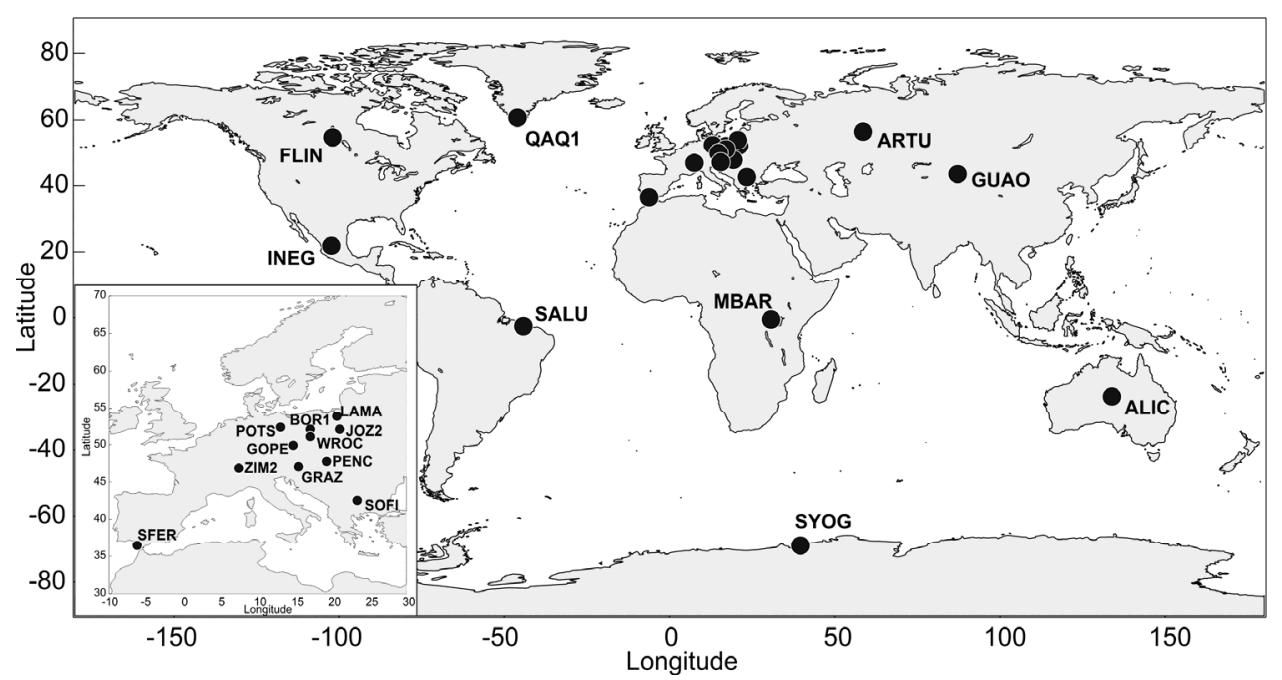

Fig. 3 The location of IGS stations chosen for the analysis.

The deformations caused by the hydrological changes are provided by the online service in the onemonth sampling; therefore, linear interpolation to the one-day sampling had to be performed. A similar interpolation was performed by Jiang et al. (2013).

The deformations caused by the APL are provided in the 6-hour sampling. We have chosen the data set from the middle epoch of the day due to the fact that GNSS coordinates are calculated in such epochs. However, the deformations caused by the NTOL are published in the 12-hour sampling (at 6:00 and 18:00). Both the epochs are averaged in order to adjust them to the epoch of the GNSS coordinates. 

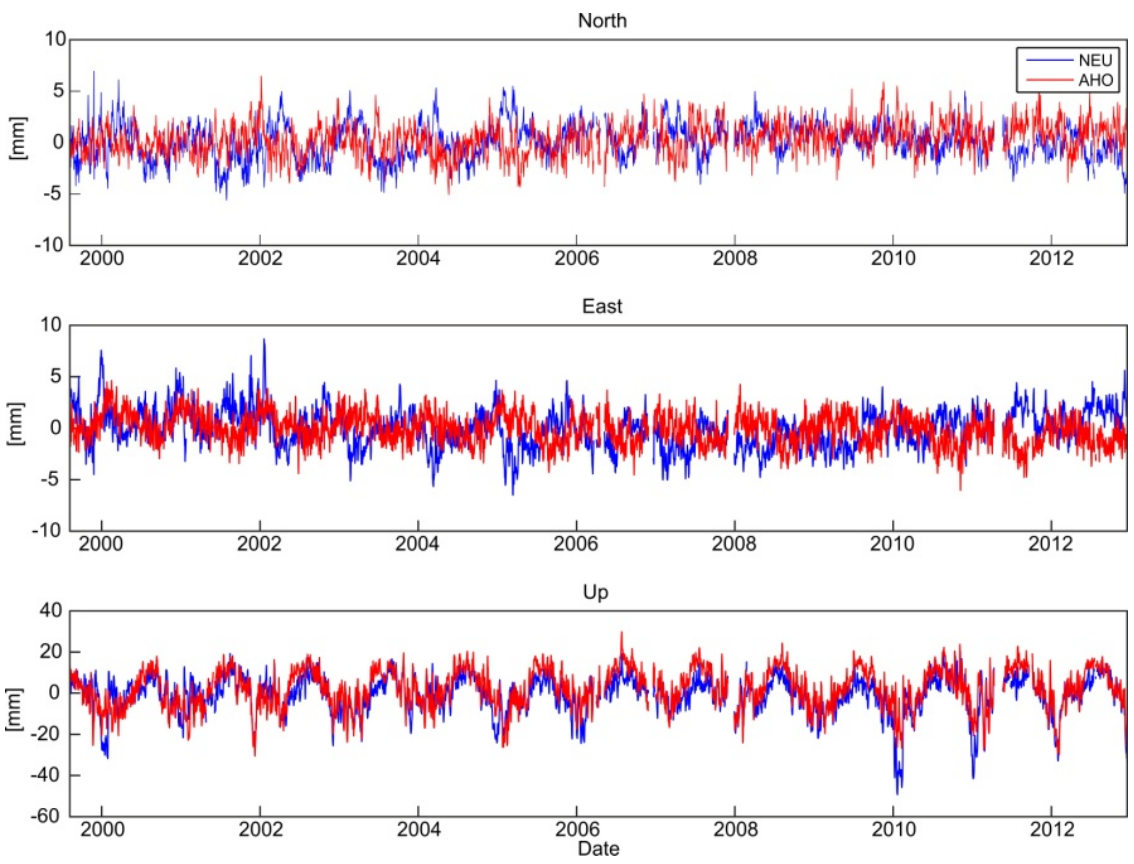

Fig. 4 Example of coordinate time series (blue) and the sum of the deformations caused by the geophysical fluids (red) for ARTU (Arti, Russian Federation) station.

The residuals of the GNSS coordinates were modelled using the sine and cosine functions in Eq. (1) for the period of 365.25 days and for constant amplitude. Additionally, the authors modelled the sum of the geophysical deformations of the Earth's crust $(\mathrm{APL}+\mathrm{NTOL}+\mathrm{HYDRO})$ in order to determine a phase shift between the analyzed signals.

In order to confirm the chosen annual signal for further research, we used wavelet analysis of the time series in the time-frequency domain (mother wavelet: Morlet).

\section{ANALYSIS}

The analyses were focused on determining periodic components for time series of coordinates, deformations of the Earth's crust, as well as the influence of deformations on coordinate changes of the analyzed GNSS stations. Figure 4 shows an exemplary diagram of the coordinate (blue) and deformation (red) time series.

For the analysis of the periodic signals, we used FFT and Eqs. (1), (2) and (3) the iLSE method. The results of the iLSE analysis are shown in Figures 5a and 5b. Based on Figure 5, one can see that the dominant period for the Up component of station coordinates is the annual period, i.e., 365.25 days, confirmation of which is the FFT analysis shown in Figures $5 \mathrm{c}$ and $5 \mathrm{~d}$.

To confirm the legitimacy of the choice of the annual period as dominant, we performed wavelet analysis of these time series. In Figure 6 we can see that the annual period has a greater magnitude than the semi-annual period. The semi-annual period is a change in time. Additionally, we can see very small magnitudes for the other periods. For further analysis we assumed that the annual period is more significant than the others.

The analysis of FFT and iLSE shows that for the horizontal components of station coordinates the annual period, typical for the Up component, is not clearly determined. Additionally, in Figure 4, we can see that the Up component is coincident in terms of the phase with the Up component of the deformations caused by the loading models. However, for the horizontal components, we can see a phase shift between the two signals. In order to compare the phase shift between the signals for each station, the authors performed the signal modelling by using Eq. (1) for an annual period (Fig. 9). The phase differences of the annual oscillation between both signals were determined using Eq. (4). The results of this comparison are presented in Figure 10.

Figure 7 shows periodic components (for time series of coordinates and deformations), which are the result of the iLSE method. It can be seen that the periodic components are different for the analyzed stations. However, the annual period is dominant, as confirmed by previous analyses.

RMS errors for estimation of the time series of coordinates and deformations are presented in Figure 8. In Figure 8, it can be seen that the RMS error estimation of a function for one year for coordinates and deformations ranges from $1.1 \mathrm{~mm}$ to $3.5 \mathrm{~mm}$ for horizontal components and $2.5 \mathrm{~mm}$ to $25.0 \mathrm{~mm}$ for height components. A large RMS value (up to $25.0 \mathrm{~mm}$ ) for the height component can result from too large geophysical anomalies, which affect changes in GNSS station coordinates and cause inaccuracies in deformation modelling. 

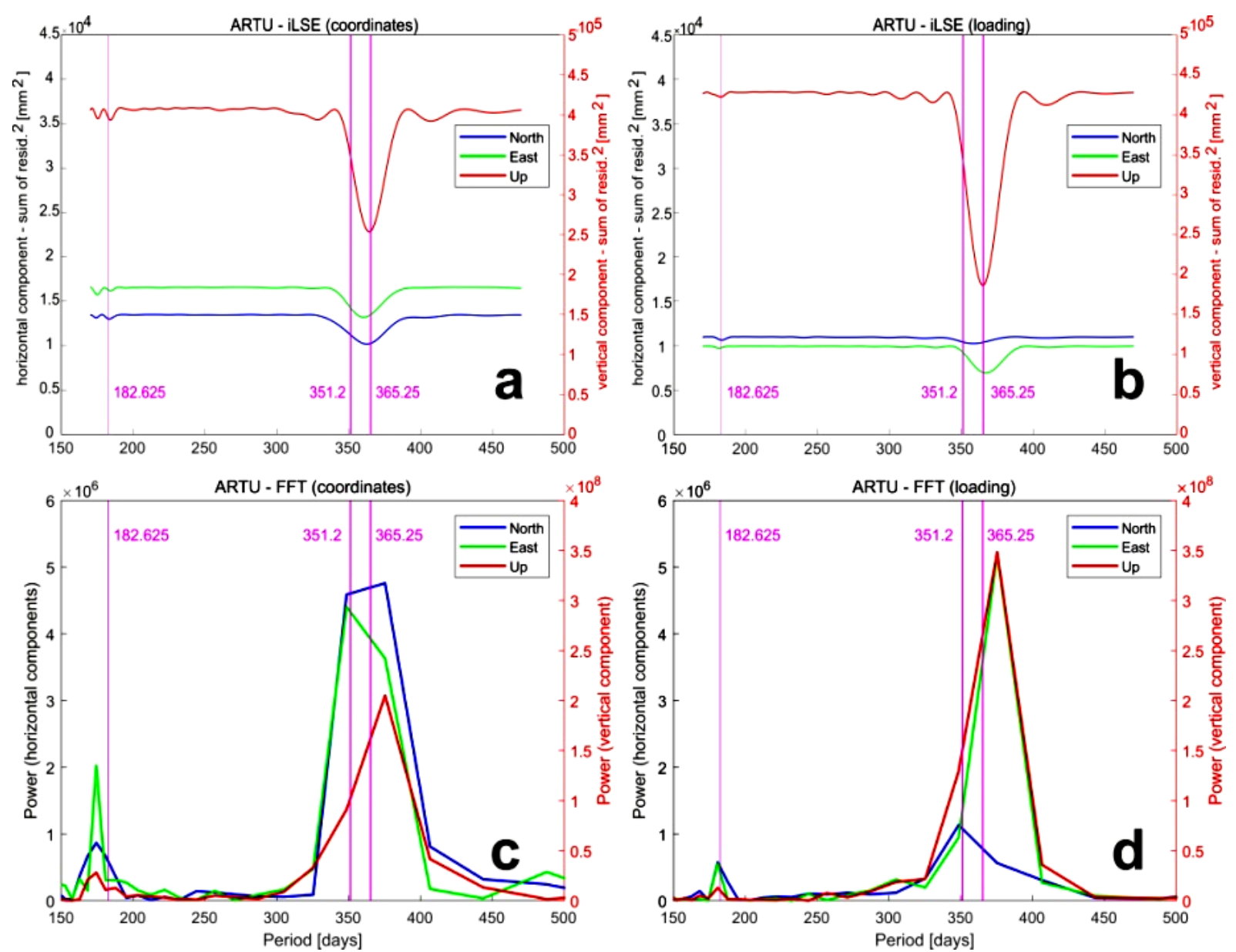

Fig. 5 Example of analysis of the periodic component for ARTU (Arti, Russian Federation) station - iLSE method (a - coordinate residuals, b - deformations from loading models) and FFT function (c coordinate residuals, $\mathrm{d}$ - deformations from loading models) - note: see different scales for horizontal and vertical components.

In Figure 10 we notice that the phase shift for the Up component of deformations and coordinates occurs in places of high hydrological anomaly. For SFER (San Fernando - Portugal) station, the phase difference reaches 32 days and it is caused by the proximity of the Atlantic Ocean, which has an impact on the changes of the Up component of station coordinates. However, SFER station is the only one station analyzed which is located close to the ocean, whereas other stations are located well inland. As a result, we cannot see similar phenomena for the Up component for other stations. Stations located in the areas characterized by the presence of hydrological anomalies (QAQ1 (Qaqortoq/Julianehaab, Greenland), SALU (São Luis, Brazil), MBAR (Mbarara, Uganda), SYOG (East Ongle Island, Antarctica)) indicate a tendency to a substantial phase shift between signals also for the Up component. This may be caused by the hydrological anomaly, which causes inaccuracies in the modelling of the deformations of the Earth's crust. For the horizontal components, the phase differences are very diverse. The deformation signals are delayed or accelerated with reference to the coordinate signals (the maxima of the annual curve of loading models occur before or after the maxima of GNSS time series). This phenomenon may be caused by the large grid model $\left(2.5^{\circ} \times 2.5^{\circ}\right)$ or the fact that the GNSS system is not sensitive to detecting environmental changes for the horizontal components. The deformation time series which we used in this analysis are a compilation of different models from different analysis centres (see Table 1). Table 2 includes the list of the correlation coefficients between the analyzed signals only for the Up component. Correlation coefficients for the horizontal components were not calculated because between time series we have the phase shift - so coefficients cannot be reliably determined.

The next step was to determine the RMS reduction values between the coordinates and the estimated deformation model. The results are included in Table 3, where it can be seen that for all the analyzed stations there was no improvement of the RMS. The smallest deterioration of the RMS value occurs for vertical components. The analysis shows that for areas with large hydrological anomalies, the RMS values are even greater by about $70 \%$ than the reference values (the reference value is the RMS calculated on the basis of the estimation of the annual signal from the coordinate time series). Deterioration of the RMS values for horizontal components is most likely the result of a phase shift between the analyzed signals. 


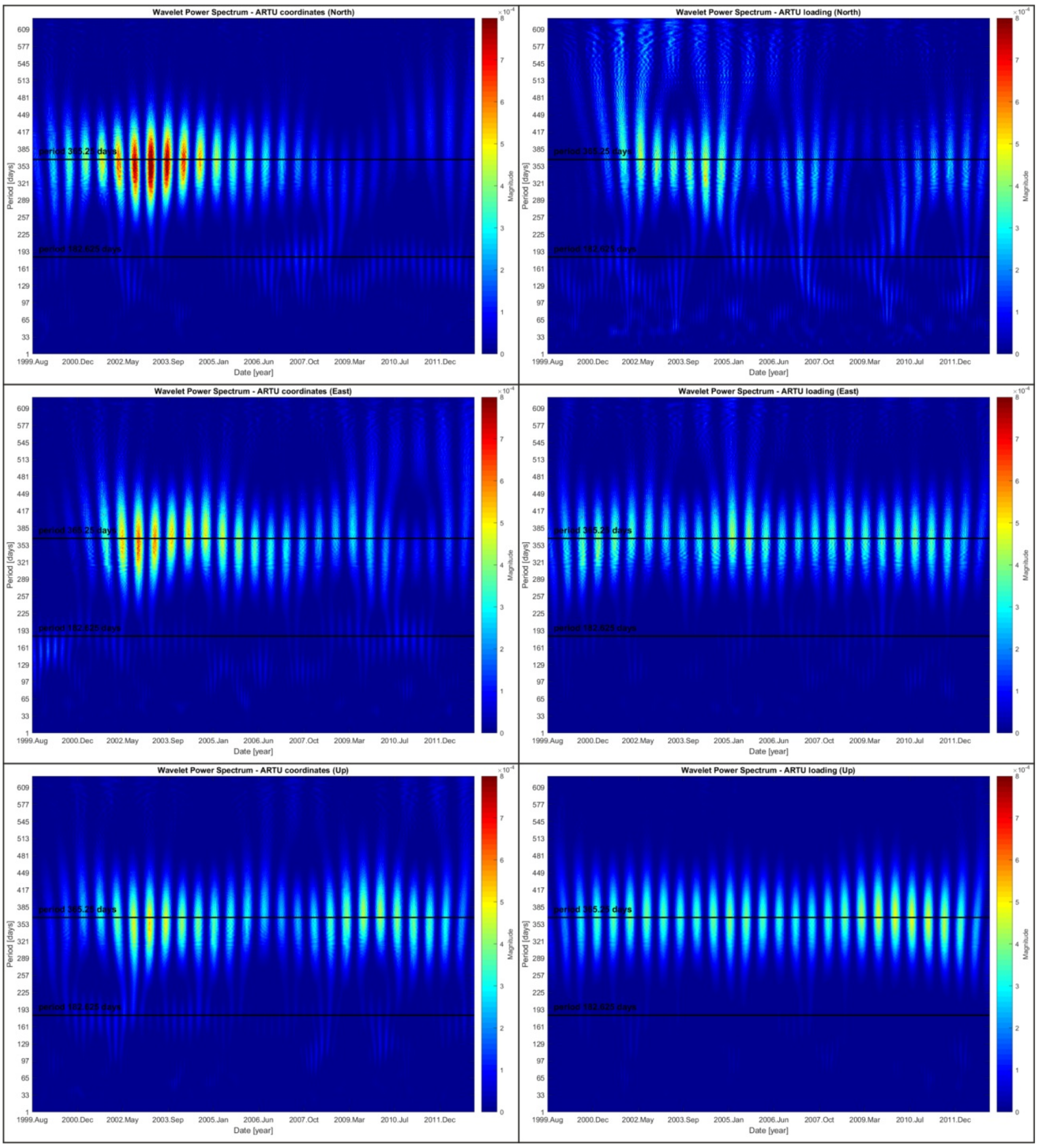

Fig. 6 Example of wavelet analysis (mother wavelet: Morlet) of the GNSS coordinate time series (left column) and deformation time series (right column) (ARTU - Arti, Russian Federation) - from above: North, East and Up component. We can see the annual signal as dominant in the time series.

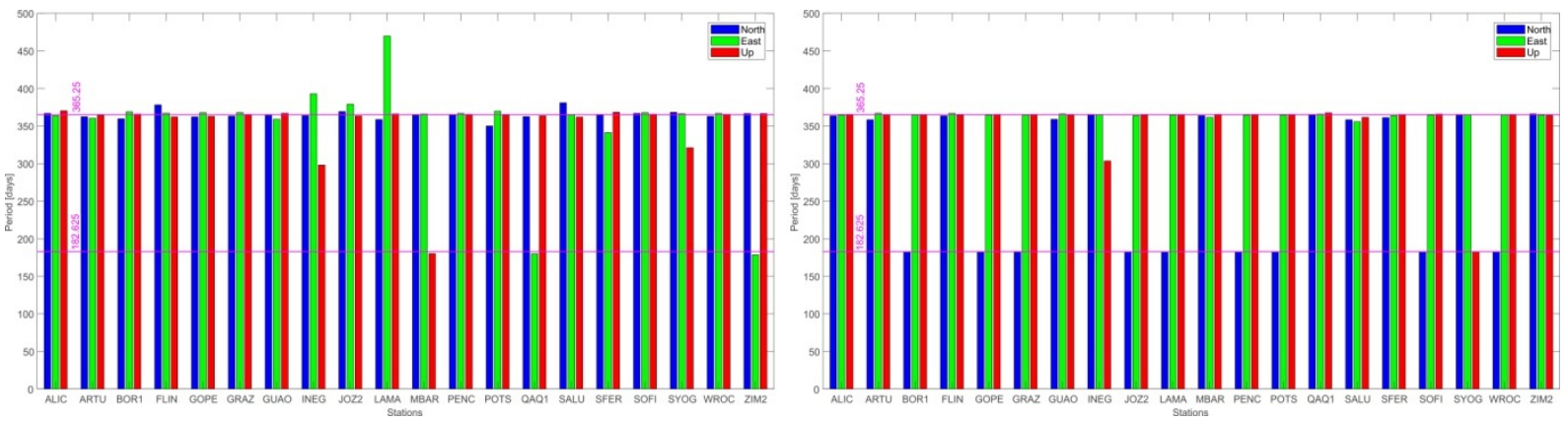

Fig. 7 Periodic components appearing in the analyzed time series: left column - coordinate time series; right column - time series of deformation. We see that the annual component is the dominant period. 

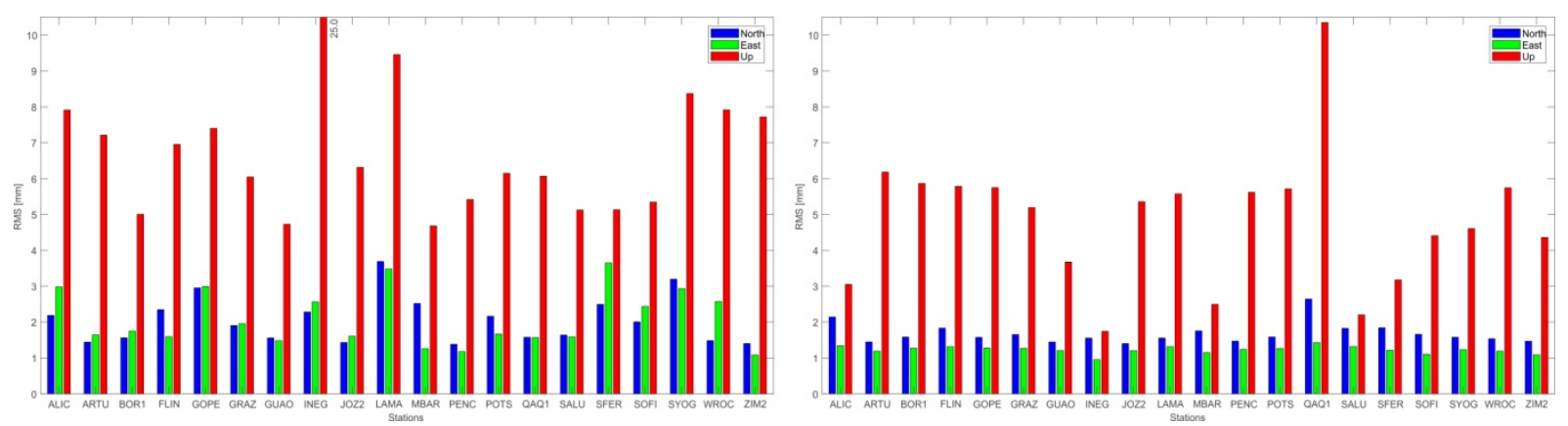

Fig. 8 RMS values of estimated time series for an annual component (left column - RMS values for coordinates, right column - RMS values for deformations).
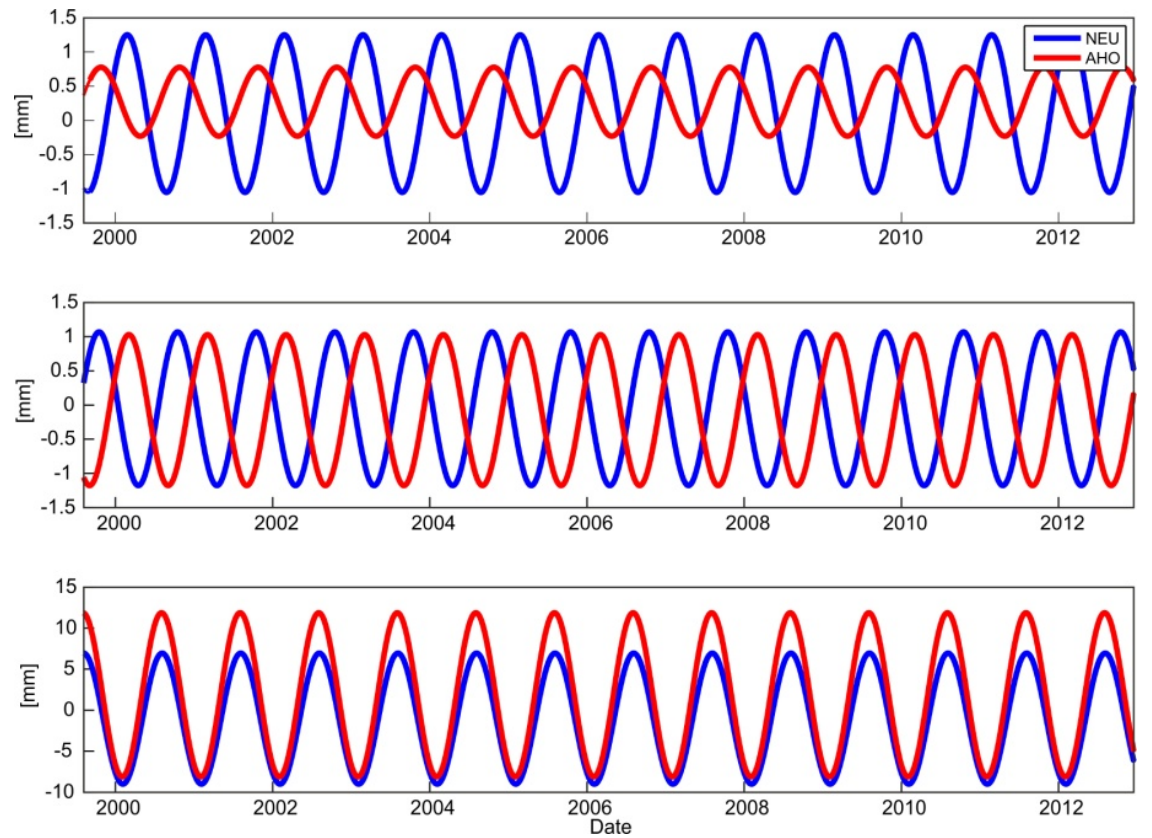

Fig. 9 Example of modelling of the analyzed signals for ARTU (Arti, Russian Federation) station: coordinates (blue), deformations (red) from the top: North, East, Up.

The last stage of the analysis was a comparison of the estimated amplitudes of the analyzed signals. In Figure 11 it can be seen that the estimated amplitudes for the deformation of the Earth's crust are almost twice as large as the amplitudes of the time series of coordinates for vertical components. For horizontal components, we do not see such large differences between the amplitudes of annual signals.

The next step of the research will be to search for the cause of the phase shift between the analyzed signals, which will allow for more accurate interpretation of the results in terms of the geodynamics of the Earth's crust for the analyzed set of IGS stations.

\section{CONCLUSIONS AND DISCUSSION}

Summarizing the current analyses, we confirm that the Up component of station coordinates is in a strong correlation with the deformations of the Earth's crust described by the loading models. However, for the horizontal components, a substantial phase shift between the two signals occurs. As previously mentioned, the reason for this phenomenon requires further investigation. The causes of the phase
Table 2 Correlation coefficients of analyzed IGS stations coordinates (Up component) and Earth's crust deformations model - absolute value.

\begin{tabular}{lc}
\hline \multicolumn{1}{c}{ Stations } & Correlation coefficient \\
\hline ALIC & 0.33 \\
ARTU & 0.79 \\
BOR1 & 0.62 \\
FLIN & 0.34 \\
GUAO & 0.56 \\
INEG & 0.27 \\
JOZ2 & 0.63 \\
LAMA & 0.19 \\
MBAR & 0.15 \\
PENC & 0.49 \\
POTS & 0.48 \\
QAQ1 & 0.07 \\
SALU & 0.67 \\
SFER & 0.36 \\
SOFI & 0.57 \\
SYOG & 0.22 \\
WROC & 0.35 \\
ZIM2 & 0.41 \\
GOPE & 0.56 \\
GRAZ & 0.63 \\
\hline
\end{tabular}



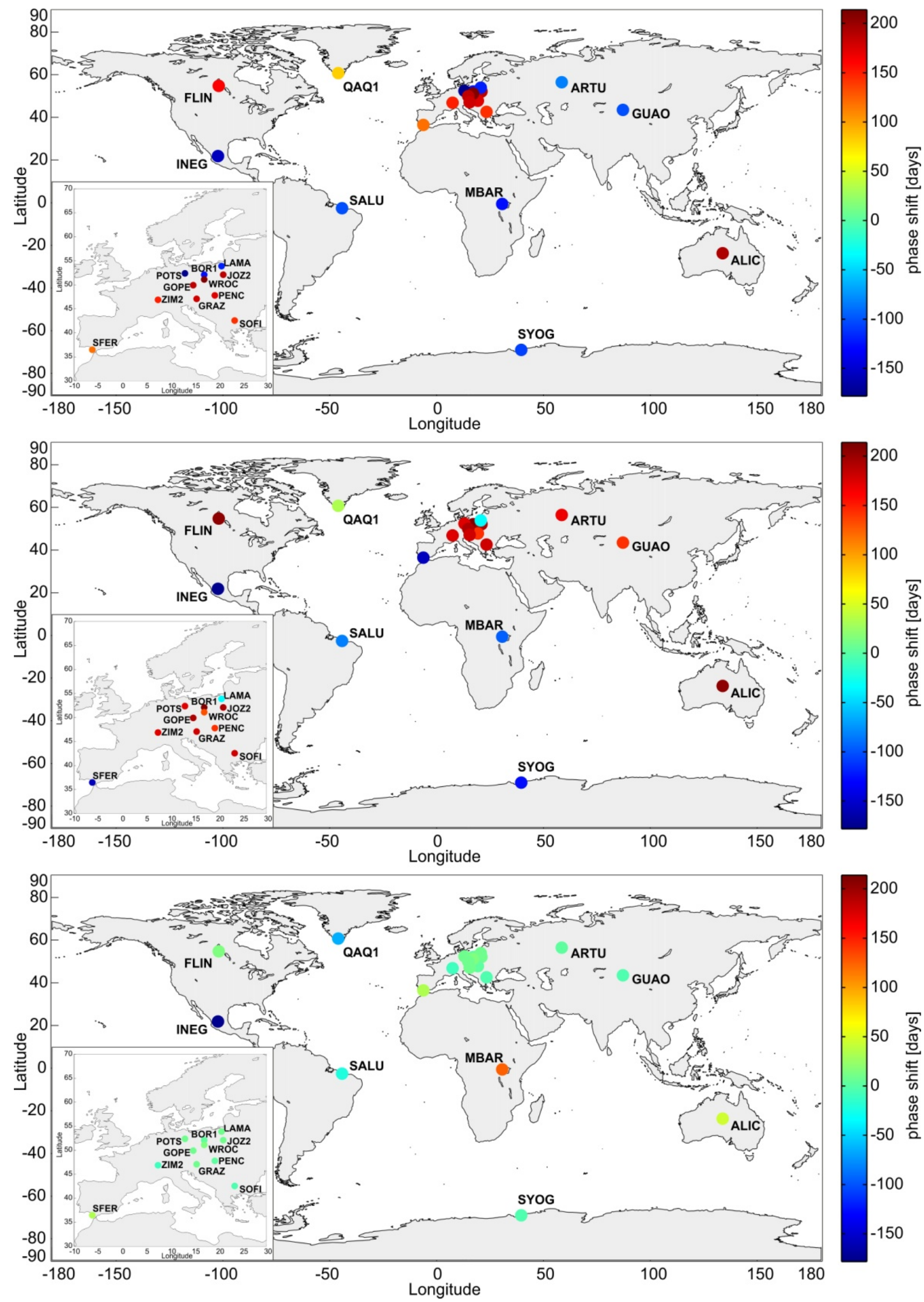

Fig. 10 Phase shifts of the annual oscillation between the analyzed signals for chosen IGS station coordinates in the (from top) North, East and Up. 
Table 3 RMS error reduction values between the coordinates and the estimated model of the Earth's crust deformation.

\begin{tabular}{lccc}
\hline Station & North (RMS reduction) [\%] & East (RMS reduction) [\%] & Up (RMS reduction) [\%] \\
\hline ARTU & 23.9 & 33.4 & 9.7 \\
BOR1 & 7.2 & 40.8 & 17.7 \\
GUAO & 77.2 & 36.4 & 16.3 \\
JOZ2 & 4.5 & 39.7 & 5.8 \\
LAMA & 4.0 & 4.3 & 4.7 \\
PENC & 8.8 & 36.4 & 6.3 \\
POTS & 3.6 & 34.1 & 8.2 \\
SFER & 8.2 & 8.8 & 7.5 \\
SOFI & 5.8 & 15.2 & 5.8 \\
WROC & 10.4 & 14.3 & 4.1 \\
ZIM2 & 17.3 & 61.9 & 6.3 \\
FLIN & 38.1 & $3 ., 2$ & 3.2 \\
INEG & 22.6 & 6.0 & 1.4 \\
SALU & 120.6 & 57.7 & 21.4 \\
ALIC & 32.7 & 21.1 & 3.2 \\
QAQ1 & 31.0 & 31.8 & 4.4 \\
MBAR & 38.5 & 27.2 & 4.3 \\
SYOG & 40.5 & 11.0 & 0.4 \\
GOPE & 2.4 & 13.3 & 10.0 \\
GRAZ & 12.8 & 25.4 & 8.7 \\
\hline
\end{tabular}

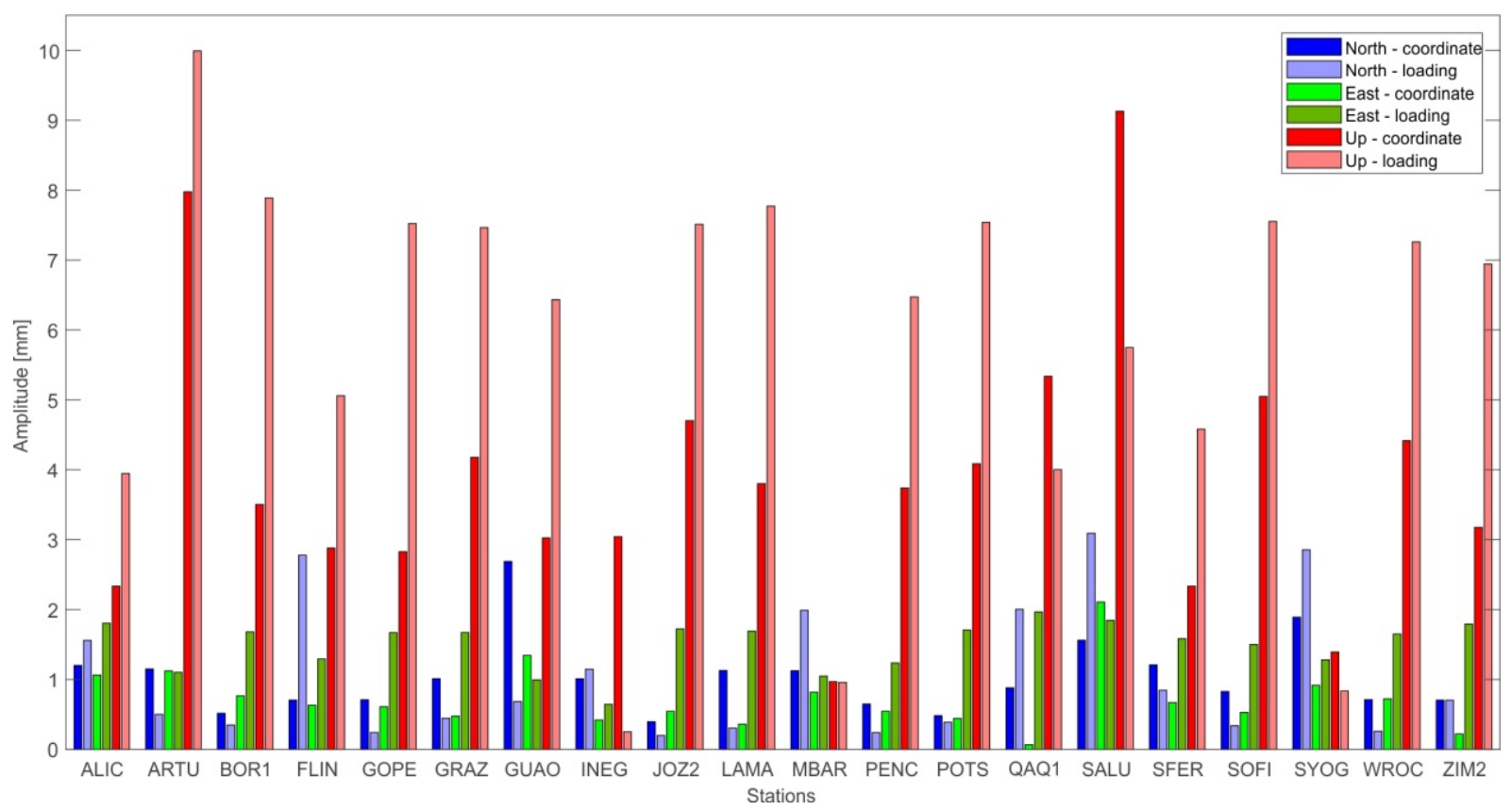

Fig. 11 Comparison of the annual amplitudes of the analyzed signals - the time series of coordinates and the time series of deformation of the Earth's crust from loading models. The graph shows that the amplitudes of annual signalsfor the deformation model are two times greater than the amplitudes estimated from coordinates.

shift for the horizontal components can be significant at the level of the loading corrections during the reprocessing of the archival GNSS data.

The present analyses focused on the model of deformation of the Earth's crust, supplying these deformations in the form of North, Earth's and Up values. This model is a compilation of several loading models. The analyses were aimed at determining its suitability for correcting the impact of Earth crust deformation on coordinate changes at GNSS stations for the North, East and Up components. This article analyzes the sum of deformations of the Earth's crust from the loading models (APL + Hydro + NTOL).

When analyzing phase shifts for horizontal components, it can be assumed that in the coordinate time series there may be other periodic components than in models of deformation of the Earth's crust, or that the compilation of different loading models may cause such artifacts. Such a phenomenon may also be indicative of unidentified periodic components or local anomalies at the locations where the GNSS stations are installed. As previously mentioned, the 
RMS values deteriorated in relation to the reference values. In the literature described in the Introduction, the authors managed to improve the RMS value (taking into account corrections to coordinates) for GNSS stations (Up component). It should be noted that the authors have used other loading models.

In their work, Collilieux et al. (2009) present, among others, the amplitude of annual signals for VLBI, SLR and GNSS stations with corrections and without corrections of the loading models. Their analysis showed that the amplitudes of the annual signals (without corrections) for GNSS stations are up to $2.5 \mathrm{~mm}$, up to $2.5 \mathrm{~mm}$ and up to $10 \mathrm{~mm}$ for North, East and Up respectively. Taking into account the corrections to the coordinates, the amplitude change occurred only for the height component (amplitude value up to $8 \mathrm{~mm}$ ). In this article, the calculated amplitudes for horizontal components are from 1.1$2.8 \mathrm{~mm}$ (GNSS) and 1.5-3.5 mm (loading model). However, for vertical components, the amplitude values for GNSS are 2.2-9 $\mathrm{mm}$, and for the Loading model $4.0-10 \mathrm{~mm}$. We see that the above amplitude values coincide with those presented by Collilieux et al. (2009).

Van Dam et al. (2007) in their work compared the amplitudes of the annual components, as well as the phases of GNSS and GRACE signals for the vertical component. Analyses have shown that the amplitudes and phases are not coherent. Similar results were obtained by the authors of this article for the vertical component, with the difference that a shift in phase occurs for stations in locations with large hydrological anomalies.

In the periodic components analysis, iLSE, FFT and wavelet analysis were used. All these methods confirmed the reasonableness of selecting the annual component as the dominant signal in the time series of coordinates and deformations.

\section{ACKNOWLEDGEMENTS}

The authors would like to thank Wroclaw Center for Networking and Supercomputing (http://www.wcss.wroc.pl/; computational grant using Matlab Software License No: 101979). The research was financed from statutory funds for young scientists from the Faculty of Environmental Engineering and Geodesy, Wroclaw University of Environmental and Life Sciences (grant no B030/0110/17).

\section{REFERENCES}

Bogusz, J. and Kontny, B.: 2011, Estimation of the subdiurnal noise level in GPS time series. Acta Geodyn.Geomater., 8, 3(163), 273-281.

Bogusz, J., Figurski, M., Kontny, B. and Grzempowski, P.: 2012, Horizontal velocity field derived from EPN and ASG-EUPOS satellite data on the example of southwestern part of Poland. Acta Geodyn.Geomater., 9, 3(167), 349-357.
Bos, M. S., Bastos, L. and Fernandes, R. M. S.: 2010, The influence of seasonal signals on the estimation of the tectonic motion in short continuous GPS time-series. J. Geodyn., 49, 3-4, 205-209. DOI: 10.1016/j.jog.2009.10.005

Collilieux, X., Altamimi, Z., Coulot, D., van Dam, T. and Ray, J.: 2010, Impact of loading effects on determination of the International Terrestrial Reference Frame. Adv. Space Res., 45, 1, 144-154. DOI: 10.1016/j.asr.2009.08.024

Dach, R. and Walser, P.: 2015, Bernese GNSS Software Version 5.2.

Dong, D., Fang, P., Bock, Y., Cheng, M. K. and Miyazaki, S.: 2002, Anatomy of apparent seasonal variations from GPS - derived site position time series. J. Geophys. Res., Solid Earth, 107, B4, ETG 9-1-ETG 916. DOI: $10.1029 / 2001 J B 000573$

Dow, J.M., Neilan, R.E. and Rizos, C.: 2009, The International GNSS Service in a changing landscape of Global Navigation Satellite Systems. J. Geod., 83, 3-4, 191-198. DOI: 10.1007/s00190-008-0300-3

Jiang, W., Li, Z., van Dam, T. and Ding, W.: 2013, Comparative analysis of different environmental loading methods and their impacts on the GPS height time series. J. Geod., 87, 7, 687-703. DOI: $10.1007 / \mathrm{s} 00190-013-0642-3$

King, M., Moore, P., Clarke, P. and Lavallée, D.: 2006, Choice of optimal averaging radii for temporal GRACE gravity solutions, a comparison with GPS and satellite altimetry. Geophys. J. Int., 166, 1, 1-11. DOI: $10.1111 / j .1365-246 X .2006 .03017 . x$

Klos, A., Bogusz, J., Figurski, M. and Kosek, W.: 2014, Irregular variations in GPS time series by probability and noise analysis. Surv. Rev., 47, 342, 163-173. DOI: 10.1179/1752270614Y.0000000133

Klos, A., Bogusz, J., Figurski, M. and Kosek, W.: 2015, On the handling of outliers in the GNSS time series by means of the noise and probability analysis. IAG Symposia, 143, 657-664. DOI: $10.1007 / 1345 \quad 201578$

Klos, A., Olivares, G., Teferle, F.N., Hunegnaw, A. and Bogusz, J.: 2018, On the combined effect of periodic signals and colored noise on velocity uncertainties. GPS Solut., 22, 1, 1-13. DOI: $10.1007 / \mathrm{s} 10291-017-0674-\mathrm{x}$

Prange, L., Orliac, E., Dach, R., Arnold, D., Beutler, G., Schaer, S. and Jäggi, A.: 2017, CODE's five-system orbit and clock solution-the challenges of multiGNSS data analysis. J. Geod., 91, 4, 345-360. DOI: $10.1007 / / \mathrm{s} 00190-016-0968-8$

Tregoning, P., Watson, C., Ramillien, G., McQueen, H. and Zhang, J.: 2009, Detecting hydrologic deformation using GRACE and GPS. Geophys. Res. Lett., 36, L15401. DOI: 10.1029/2009GL038718

van Dam, T., Wahr, J. and Lavallée, D.: 2007, A comparison of annual vertical crustal displacements from GPS and Gravity Recovery and Climate Experiment (GRACE) over Europe. J. Geophys. Res., Solid Earth,112, B03404. DOI: 10.1029/2006JB004335

Williams, S.D.P., Bock, Y., Fang. P. et al.: 2004, Error analysis of continuous GPS position time series. J. Geophys. Res., Solid Earth, 109, B3. DOI: 10.1029/2003JB002741 